\title{
28 Research Suare \\ The Dynamics of Neutralizing Antibody Level in One Year After SARS-CoV-2 Infection
}

\section{Dan Liang}

Guangdong Provincial Center for Disease Control and Prevention

\section{Guanting Zhang}

Sun Yat-sen University

\section{Mingxing Huang}

The Fifth Affiliated Hospital of Sun Yat-sen University

\section{Wenshan Hong}

Shantou University Medical College

\section{An'an Li}

Southern Medical University

\section{Yufeng Liang}

Southern Medical University

\section{Tao Wang}

Shantou University Medical College

Jiahui Lu

The Fifth Affiliated Hospital of Sun Yat-sen University

\section{Mengdang Ou}

The Fifth Affiliated Hospital of Sun Yat-sen University

\section{Zhongqiang Ren}

Second People's Hospital of Zhongshan

\section{Huiyi Lu}

Second People's Hospital of Zhongshan

\section{Rutian Zheng}

Huizhou Central Hospital

\section{Xionghui Cai}

Huizhou Central Hospital

\section{Xingfei Pan}

the Third Affiliated Hospital of Guangzhou Medical University

\section{Jinyu Xia}

The Fifth Affiliated Hospital of Sun Yat-sen University

Changwen Ke ( $\sim$ kecw1965@aliyun.com)

Sun Yat-sen University 


\section{Research Article}

Keywords: dynamics, SARS-CoV-2, COVID-19, neutralizing antibody

Posted Date: August 4th, 2021

DOI: https://doi.org/10.21203/rs.3.rs-731817/v1

License: (c) (i) This work is licensed under a Creative Commons Attribution 4.0 International License. Read Full License 


\section{Abstract}

Background: A lot of recent researches have focused on the duration of the nature immunity elicited by severe acute respiratory syndrome coronavirus 2 (SARS-CoV-2) infection. An improved understanding of the immunity offered by the antibodies developed against SARS-CoV-2 in recovered patients is critical for the development of diagnostic tests and vaccines. Methods: We enrolled 114 donors, which providing blood samples after discharge for half a year and one year. Neutralizing antibodies (NAbs) were tested using a micro-neutralization assay. Results: In two tests, 82 of 114 recovered patients completed the first test half a year after discharge and NAbs remained detectable in the vast majority of patients $(75 / 82$, $91.46 \%)$. In the comparison of the two intervals, $50 \%$ (27/54) of individuals had increased NAbs titers. when $31.48 \%$ (17/54) of patients remained unchanged. Conclusion: Our results suggest that immune ability is acquired in most individuals infected with SARS-CoV-2 and is sustained in a majority of patients for up to a year after recovery.

\section{Background}

Severe acute respiratory syndrome coronavirus (SARS-CoV-2), the pathogenic agent of coronavirus disease 2019 (COVID-19), is provoking a significant psychological, epidemiological, and economic burden all over the world (1). As of June 10, 2021, the disease has caused 174,061,995 confirmed cases and $3,758,560$ deaths globally (2). A study estimated antibody titers to the Middle East respiratory syndrome coronavirus (MERS-CoV) in the years after infection. Robust antibody results were discovered in those individuals with severe disease (3). Another study assessing the immune response in people with SARSCoV-2 revealed neutralizing antibodies (NAbs) in patients obtained detectable for one year after infection (4).

In this study, we characterize the kinetics of NAbs titer in one year after SARS-CoV-2 infection by a microneutralization assay. We evaluated the span it takes for recovery to become seropositive or return to seronegative. Simultaneously, we attempted to find out the factors affecting the NAbs titers.

\section{Methods}

We perform a follow-up study in three sentinel hospitals, including Huizhou People's Hospital, the Fifth Affiliated Hospital of Sun Yat-sen University, and Second People's Hospital of Zhongshan. Patients recovered from COVID-19 were enrolled and provided written informed consent. Demographic characteristics and clinical information were collected accordingly from the electronic medical record. Participants provided blood samples after discharge for half a year and one year. We accessed the heatinactivated serum samples $\left(56^{\circ} \mathrm{C}\right.$ for 30 minutes) for the presence of SARS-CoV-2 NAbs by a whole virus replication assay (Appendix.1) using SARS-CoV-2 strain (No.20SF014) isolated by the laboratory of the Institute of Pathogenic Microbiology of GDCDC. Microscopy examination was performed on day 4 to assess the cytopathic effect (CPE). NAbs titers are regarded as the highest dilution that protected more than half of cells from CPE. 


\section{Statistical analysis}

We used Geometric Mean Titer (GMT) to represent the mean value of Nab titers. The Difference of NAbs titers between groups was compared by the Chi-square test, Kruskal-Wallis Test, and Analysis of variance. Two-tailed $P$ values of $<0.05$ indicated statistical significance throughout the study.

\section{Results}

A total of 114 patients were enrolled, for these cases (median age, (37.66 \pm 1.57 ) years; IQR, 6 months-73 years), and more than half of the patients were female (58, 50.88\%). Eighteen (18/114, 15.79 percent) were asymptomatic cases, and 80 out of 114 were moderate cases. The average disease progression was 23.09 days, and it in males was higher than that in females ( 25.06 vs. 22.87). In two tests, 82 of 114 individuals completed the first test half a year after discharge and NAbs remained detectable in the vast majority of patients $(75 / 82,91.46 \%) .84$ were detected one year after discharge and they became undetectable in 0.11 percent of people. The GMT of the second interval was slightly lower than that of the first test (Table 1). 
Table 1

Demographic and clinical characteristics of patients with COVID-19.

\begin{tabular}{|c|c|c|c|}
\hline & $\begin{array}{l}\text { Male } \\
(n=56)\end{array}$ & $\begin{array}{l}\text { Female } \\
(n=58)\end{array}$ & $\begin{array}{l}\text { Total } \\
(n=114)\end{array}$ \\
\hline \multicolumn{4}{|l|}{ Age, years } \\
\hline$<18$ & 10 & 4 & 14 \\
\hline $18-59$ & 43 & 51 & 94 \\
\hline$\geq 60$ & 3 & 3 & 6 \\
\hline Mean age & & & $37.66 \pm 1.57$ \\
\hline \multicolumn{4}{|l|}{ Clinical classification } \\
\hline Asymptomatic case & 9 & 9 & 18 \\
\hline Mild case & 7 & 9 & 16 \\
\hline Moderate case & 40 & 40 & 80 \\
\hline \multicolumn{4}{|l|}{ NAbs titer } \\
\hline \multicolumn{4}{|l|}{ Half a year after discharge $(n=82)$} \\
\hline Seronegative $(<1: 4)$ & 4 & 3 & 7 \\
\hline Seropositive ( $\left.\log _{2} \mathrm{NAbs}\right)$ & 37 & 38 & 75 \\
\hline $2-4$ & 19 & 16 & 35 \\
\hline $5-7$ & 14 & 21 & 35 \\
\hline$\geq 8$ & 4 & 1 & 5 \\
\hline GMT & & & $1: 23.21$ \\
\hline \multicolumn{4}{|l|}{ One year after discharge $(n=84)$} \\
\hline Seronegative $(<1: 4)$ & 6 & 3 & 9 \\
\hline Seropositive ( $\left.\log _{2} N A b s\right)$ & 33 & 42 & 75 \\
\hline $2-4$ & 18 & 23 & 41 \\
\hline $5-7$ & 14 & 19 & 33 \\
\hline$\geq 8$ & 1 & 0 & 1 \\
\hline GMT & & & 1:17.09 \\
\hline Average disease progression (day) & 25.06 & 22.87 & 23.9 \\
\hline
\end{tabular}


In the comparison of the two intervals, 27 out of 54 individuals had increased NAbs titers when $31.48 \%$ $(17 / 54)$ of patients remained unchanged. There were statistical significances, comparisons of different NAbs titer groups in gender, age, clinical classification, and disease progression (Table 2).

Table 2

Comparison of different NAbs titer groups in gender, age, clinical classification and disease progression

\begin{tabular}{|c|c|c|c|c|c|}
\hline \multirow[b]{2}{*}{$\begin{array}{l}\text { Total } \\
\text { (male/female) }\end{array}$} & & \multirow{2}{*}{$\begin{array}{l}\text { Decreased } \\
\text { group }{ }^{1}\end{array}$} & \multirow{2}{*}{$\begin{array}{l}\text { Increased } \\
\text { group } 2 \\
27(12 / 15)\end{array}$} & \multicolumn{2}{|c|}{$\begin{array}{l}\text { Same group }{ }^{3} p- \\
\text { value }\end{array}$} \\
\hline & & & & 17(7/10) & 0.302 \\
\hline Age (year) & & $37.7 \pm 6.66$ & $40.8 \pm 7.18$ & $\begin{array}{l}24.5 \pm \\
8.21\end{array}$ & $0.026^{a^{*}}$ \\
\hline \multirow[t]{3}{*}{$\begin{array}{l}\text { Clinical } \\
\text { classification }\end{array}$} & $\begin{array}{l}\text { Asymptomatic } \\
\text { case }\end{array}$ & 6 & 5 & 1 & $0.003^{b^{*}}$ \\
\hline & Mild case & 2 & 3 & 5 & \\
\hline & Moderate case & 1 & 18 & 11 & \\
\hline $\begin{array}{l}\text { Disease } \\
\text { progression }\end{array}$ & & 20.69 & 27.88 & 29.89 & $0.015^{c^{*}}$ \\
\hline
\end{tabular}

${ }^{1}$ : represented the NAbs titers after one year were lower than those after half a year.

2. remarked the NAbs titers after one year were higher than those after half a year.

3: indicated the NAbs titers after one year were consistent with those after half a year.

*: meant a statistically significant result.

a. For the age group, the Mann-Whitney $U$ test showed that there were significant differences between "Decreased group" and "Same group" $(P=0.022)$ and "Increased group" $(P=0.010)$

b: for clinical classification, the Mann-Whitney Utest showed that there were significant differences between "Increased group" and "Same group" $(P=0.002)$ and "Decreased group" $(P=0.001)$

c: for the disease progression, the Mann-Whitney $U$ test showed that there was a significant difference between "Decreased group" and "Increased group" ( $P=0.015)$

In addition, 54 survivors who participated in the whole follow-up period were included in the further analysis, and their NAbs became undetectable in $9.26 \%$ of patients at the second interval. More than half of the cases $(32 / 54,59.26 \%)$ were moderate cases, and the difference between them was statistically significant in two intervals $(P<0.05)$ (Fig. 1).

\section{Discussion}


Given the limitations of our research and a conservative interpretation method, our results demonstrated that the Nabs of most survivors still had detectable, although a slight decrease in NAbs titer in a fraction number of individuals one year after discharge, which is the similar described previously in SARS-CoV study (4-6); this finding is comforting because NAbs play a critical role in protection against infection. Additional study is needed to support it, including the duration of memory B cells in vivo (7). In addition, to better treat COVID-19 patients in clinical practice, the National Health Commission of the People's Republic of China incorporated the recovery plasma therapy into the Trial 8th Edition diagnosis and treatment program of Novel coronavirus pneumonia; based on this, NAbs titers in two tests were artificially divided and analyzed in the trend of change, in order to provide a foundation for screening donors and collecting convalescent plasma with higher NAbs titer $(8,9)$.

\section{Conclusions}

Our results suggest that immune ability is acquired in most individuals infected with SARS-CoV-2 and is sustained in a majority of patients for up to a year after recovery.

\section{Abbreviations}

SARS- CoV-2

Severe Acute Respiratory Syndrome Coronavirus 2

COVID-19

Coronavirus Disease 2019

Nabs

Neutralizing antibodies

MERS-CoV

Middle East respiratory syndrome coronavirus

CPE

cytopathic effect

GMT

Geometric Mean Titer

\section{Declarations}

\section{Ethics approval and consent to participate}

All procedures were approved by the Ethical Committee of the Guangdong Provincial Center for disease control and prevention (ethics approval number:W96-027E-202121). All methods were carried out in accordance with relevant guidelines and regulations. All included patients were provided with written informed consent for anonymous collection and analysis of clinical data.

\section{Consent for publication}


Not applicable.

\section{Availability of data and material}

The datasets used and/or analysed during the current study are available from the corresponding author on reasonable request.

\section{Competing interests}

The authors declare that they have no competing interests.

\section{Funding}

Bio-land Laboratory (Project No. EKPG21-27) and Sino-German Center for Research Promotion (SGC)'s Rapid Response Funding Call for Bilateral Collaborative Proposals Between China and Germany in COVID-19 Related Research (Project No. C-0032) financially supported this study, including costs for students' remuneration who joined study performance and the costs of instruments. The funding body has no role in study design, data collection, \& interpretation, and manuscript writing. All authors together declare that there was no other financial compete to disclose.

\section{Authors' contributions}

DL performed a micro-neutralization assay, drew figures, wrote the manuscript, and interpreted the results. GZ undertook data analysis and statistics, performed the literature search, and completed statistical tables. WH, AL, YL, TW, and GZ performed a micro-neutralization assay and recorded the results. JL, MH, MO, JX, ZR, and HL, and RZ and XC, and XP collected and collated the basic information of patients. CK designed the whole study framework and took responsibility for the integrity and accuracy of the data. All authors have approved the submitted version and agreed both to be personally accountable for the author's own contributions and to ensure that questions related to the accuracy or integrity of any part of the work.

\section{Acknowledgments}

Not applicable.

\section{References}

[1]. V'Kovski P, Kratzel A, Steiner S, Stalder H. Coronavirus biology and replication: implications for SARS-CoV-2. 2021 Mar;19(3):155-70.

[2]. Organization WH. World Health Organization/Home/Diseases/ Coronavirus Disease (COVID19)/Number at a glance https://www.who.int/emergencies/diseases/novel-coronavirus-2019. 2021 Jun.. 
[3]. Choe PG, Perera R, Park WB, Song KH, Bang JH, Kim ES, et al. MERS-CoV Antibody Responses 1 Year after Symptom Onset, South Korea, 2015. Emerg Infect Dis. 2017 Jul;23(7):1079-84.

[4]. Liu W, Fontanet A, Zhang PH, Zhan L, Xin ZT, Baril L, et al. Two-year prospective study of the humoral immune response of patients with severe acute respiratory syndrome. The Journal of infectious diseases. 2006 Mar 15;193(6):792-5.

[5]. Tang F, Quan Y, Xin ZT, Wrammert J, Ma MJ, Lv H, et al. Lack of peripheral memory B cell responses in recovered patients with severe acute respiratory syndrome: a six-year follow-up study. Journal of immunology (Baltimore, Md : 1950). 2011 Jun 15;186(12):7264-8.

[6]. Yang LT, Peng H, Zhu ZL, Li G, Huang ZT, Zhao ZX, et al. Long-lived effector/central memory T-cell responses to severe acute respiratory syndrome coronavirus (SARS-CoV) $S$ antigen in recovered SARS patients. Clinical immunology (Orlando, Fla). 2006 Aug;120(2):171-8.

[7]. Long QX, Liu BZ, Deng HJ. Antibody responses to SARS-CoV-2 in patients with COVID-19. 2020 Jun;26(6):845-8.

[8]. China NHCotPsRo. Trial 8th Edition diagnosis and treatment program of Novel coronavirus pneumonia http://www.nhc.gov.cn/xcs/zhengcwj/202104/7de0b3837c8b4606a0594aeb0105232b.shtml. 2021 Apr..

[9]. Ming JMYRZXR. Observation on IgG antibody titer in plasma donated by recovered COVID-19 patients, Wuhan (in Chinese). Chin J Blood Transfusion 2020 Aug;33(8):755-7.

\section{Figures}




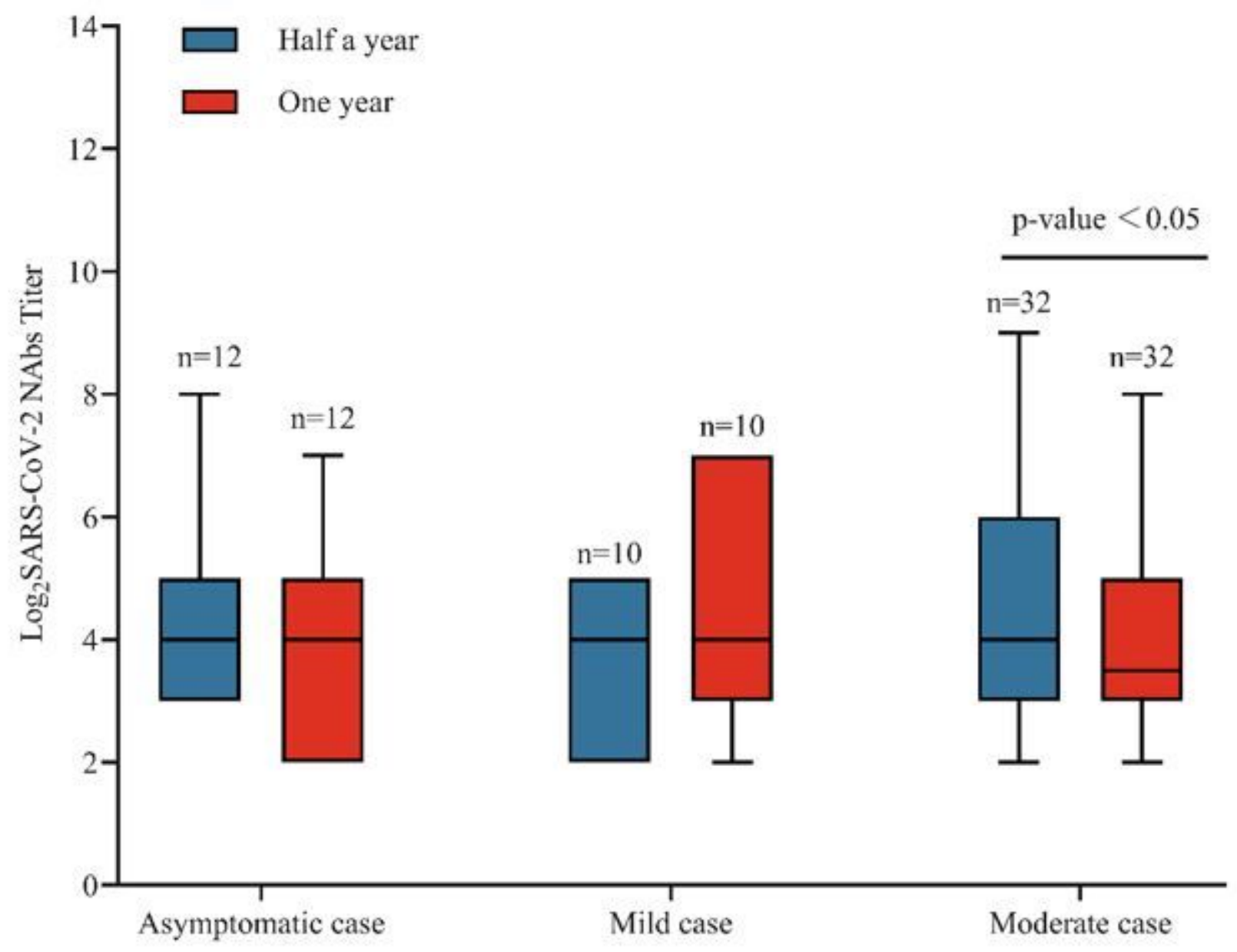

Figure 1

NAbs titer distribution of different clinical classifications at two intervals. NAbs titers were log2 processed.

\section{Supplementary Files}

This is a list of supplementary files associated with this preprint. Click to download.

- Additionalfile1.docx 